\title{
Limited Intersectional Approaches to Veteran and Former Prisoner Reintegration: Examining Gender Identity and Sexual Orientation
}

\section{Brittany N. Dernberger}

University of Maryland

\begin{abstract}
Recent legal and policy changes within two prominent institutions, the military and criminal justice system, have profoundly altered the visibility - and subsequent rights of lesbian, gay, bisexual, and transgender (LGBT) service members and those currently incarcerated. Comparing these two institutions side-by-side illustrates how LGBT inequality mechanisms operate at both an individual and systemic level. Both the military and criminal justice system are total, hypermasculine institutions, both are socially concentrated experiences, both end with a changed relationship with the state, and both veterans and those formerly incarcerated have comparable challenges to reintegration upon returning to their communities. Intersectional analysis provides an apt tool to critically examine how reintegration processes differ for those identifying as LGBT. I examine ways in which existing literature is intersectional and highlight the lack of analyses about systems of power that amplify or moderate former prisoner re-entry and veteran transition for those identifying as LGBT. Finally, I discuss why there may be a lack of attention to intersectionality, and specifically to LGBT individuals, in the literature and address how an intersectional framework would contribute to both public policy and to expanding the existing literature on social inequality and stratification.
\end{abstract}

Keywords: LGBT, sexual orientation, gender identity, intersectionality, ex-offender re-entry, former prisoner, veteran reintegration, stratification 


\section{INTRODUCTION}

Recent legal and policy decisions within two prominent institutions, the military and criminal justice system, have profoundly altered the visibility - and subsequent rights - of lesbian, gay, bisexual, and transgender (LGBT) service members and those currently incarcerated. The experience of LGBT individuals as they exit these institutions, as veterans and as those marked by a criminal record (Pager 2003), will likely differ from those who fit the typical image of a veteran or former prisoner. ${ }^{1}$ Depicting the prison and military institutions side-byside illustrates how gender and LGBT inequality mechanisms operate at both an individual and systemic level. The military and criminal justice systems have several parallels: both entities are total, hypermasculine institutions, both are socially concentrated experiences, and both end with a changed relationship with the state. Furthermore, both veterans and those formerly incarcerated have comparable challenges to reintegration upon returning to their communities. Intersectional analysis provides an apt tool to critically examine how these processes differ for those with marginalized gender identities and sexual orientations. While the prison and military are historically heterosexual and male-dominated institutions, this is changing, as demonstrated by several recent LGBT-related policies and reforms.

\section{RE-ENTRY FOR THE FORMERLY INCARCERATED: INCREASED ATTENTION TO LGBT INMATES}

Mass incarceration has been a prevalent topic in both the sociological literature and public discourse in recent years (Alexander 2010; Coates 2015), and new laws and policies have elevated the needs of LGBT inmates. For instance, the 2003 Prison Rape Elimination Act (PREA) established standards for preventing sexual assault during

\footnotetext{
${ }^{1}$ I use the term "former prisoner" in this article to describe people who have previously been incarcerated. Other literature refers to "ex-offenders," "ex-felons," or "ex-convicts," which all have their own political history. I choose to use "formerly incarcerated" and "former prisoner" interchangeably in this article to reflect that I am specifically referring to people who have been incarcerated and to illustrate the institutional aspects of incarceration.
} 
incarceration, with the final rules going into effect on August 20, 2012 (Bureau of Justice 2015; "PREA Resource Center" 2016). In addition to increasing awareness of sexual assault, the enactment of PREA led to more gender-focused data collection efforts (PREA Resource Center 2016). This heightened gender awareness extended to the unique needs of transgender and gender non-conforming individuals while incarcerated; PREA guidelines were used in March 2016 to argue that transgender inmates should not be assigned to housing units only based on their anatomy as this heightens their risk for sexual assault (Lerner-Kinglake 2016). Instead, individuals' gender identity, gender presentation, and own feelings of where they would be safest are supposed to be taken into account when detention centers assign inmates (Lerner-Kinglake 2016). The challenges transgender inmates face have been further propelled into national attention by popular media outlets, including shows like Orange Is the New Black, which premiered in July 2013 and features transgender inmate Sophia Burset, portrayed by transgender actress Laverne Cox (Lang 2016; Sontag 2015).

These recent legal and policy changes have had significant impact on the visibility, and subsequent treatment, of individuals identifying as LGBT within the prison system, yet less attention has been paid to decarceration. Most prisoners are eventually released and what happens when individuals seek to transition back into communities remains a pressing social concern. Marginalized gender identity and sexual orientation statuses likely compound the challenges of reintegration. For example, if the public narrative about offenders maintains that a "criminal" is a straight, working class, man of color, the re-entry process may be different for a Latina who identifies as a lesbian, a white gay man, or an African American trans* woman currently transitioning (Chiricos and Eschholz 2002; Sontag 2015). The implications for this extend beyond the interpersonal level to the structural and systemic level. LGBT individuals are marginalized - within an already stigmatized and stratified system - because systems of power influence the reintegration process for those who do not fit the archetypal narrative by focusing on the dominant group. 


\section{VETERAN REINTEGRATION: MORE WOMEN AND THE REPEAL OF DADT}

The study of decarceration presents an opportunity for parallel analysis to another "de-institutionalization" process: transitioning from serving in the military to life as a civilian. A number of new policies have dramatically changed the military landscape for LGBT service members and veterans. The repeal of Don't Ask, Don't Tell (DADT) went into effect on September 20, 2011, terminating the prohibition of gay, lesbian, and bisexual service members serving openly in the military. After DADT ended, the military instituted "sexual orientation neutral" policies and refrained from discharging service members based solely on their sexual orientation (Department of Defense 2011). While the end of DADT represented a huge victory for LGB service members and veterans, transgender and gender non-conforming individuals were still barred from military service. However, the Department of Defense lifted this ban on transgender service members on June 30, 2016 (Department of Defense 2016a). These changes, coupled with the January 2016 opening of all military positions - including combat - to women, have the potential to fundamentally shift the composition of the military (Pellerin 2015).

The move from the rigid, total institution of the military back to a community bears many similarities to decarceration, yet there are clear differences of status and resources between those leaving the military and those leaving prison. The mainstream narrative again plays a role - the image of a typical veteran is a "citizen soldier:" a straight, White, working class young man who honorably served his country and has now returned home (Wright 2012). The transition process is likely different for those who do not fit this archetype, such as women, individuals discharged under DADT, or trans* veterans (Rosenberg 2015). The archetypes of a veteran as a White working-class man and a former prisoner as a Black working class man are often unstated, but shape the academic discourse on reintegration and subsequent public policy. Despite recent policy changes within the prison and military which emphasize the needs of LGBT individuals, there is little academic scholarship studying how those identifying as LGBT may have distinct transitions from these institutions, 
differing from the reintegration processes of those with more privileged identities.

Applying an intersectional lens to critically examine reintegration processes from the perspective of those with marginalized gender identities and sexual orientations can shed new light on the multiple identities individuals hold and the mutually reinforcing systems of power that influence reintegration. This article reviews the existing literature on LGBT-related reintegration for veterans and former prisoners in the United States. This review is centered around two key questions: Does the veteran and former prisoner reintegration literature include intersectional analysis, specifically related to those identifying as LGBT? Of the literature that employs intersectional analysis, does it include investigation of systems and structures, or is it primarily focused on descriptive, identity-based characteristics? After discussing the theoretical reasons for considering the reintegration processes of LGBT veterans and former prisoners in parallel, I review the major intersectional themes in the reintegration literature specific to gender identity and sexual orientation. I examine whether these empirical studies include a structural, systemic analysis (such as accounting for systems of power), or simply a descriptive additive approach to the multiple identities individuals hold (such as recognizing the intersection of gender and race). I find that while there is acknowledgement of gender and sexual orientation distinctions at the individual level, there are few analyses of the systems of power that amplify or moderate former prisoner re-entry and veteran transition for LGBT individuals. Finally, I discuss why there may be a lack of attention to intersectionality, and specifically to LGBT individuals, in the literature and address how an intersectional framework would contribute to both public policy and to expanding the existing literature on social inequality and stratification.

\section{THEORETICAL BACKGROUND: VETERAN AND FORMER PRISONER REINTEGRATION AS PARALLEL PROCESSES}

There are several reasons for depicting how deinstitutionalization, at a structural level, and reintegration processes, at an individual level, are 
similar for those exiting both the prison system and the military. Both entities are total, hypermasculine institutions, both are socially concentrated experiences, and both end with a changed relationship with the state. Furthermore, both veterans and formerly incarcerated people have comparable challenges to reintegration upon returning to their communities. This side-by-side comparison can illustrate how inequality mechanisms operate for those not in the dominant group - women and people identifying as LGBT. After highlighting the similarities of these two institutions, I discuss how an intersectional analysis, specifically with attention to gender identity and sexual orientation, provides particular analytic tools to examine how reintegration processes may differ for those who do not fit the model narrative.

\section{Total, Hypermasculine Institutions}

First, both the prison and the military represent total institutions. Goffman (1961) describes a total institution as "a place of residence and work where a large number of like-situated individuals, cut off from the wider society for an appreciable period of time, together lead an enclosed, formally administered round of life" (p. xiii). Both the prison system and the military embody these characteristics. Pager (2003) has described the way incarceration acts as an institution that stratifies young men who are then "credentialed" as a criminal $(937,942)$. The military, which has a strict hierarchy, many rules and regulations, and isolates individuals from the broader community, is also described as a stand-alone institution (Halvorson 2010). Furthermore, both of these total institutions are hypermasculine. They have patriarchal power structures, are based on masculine norms, and are majority-men institutions. Intriguingly, women make up a similar proportion of the military and incarcerated populations; women are $15 \%$ of the military and about $14 \%$ of jail inmates, ${ }^{2}$ presenting another apt reason for comparison of these institutions (Office of the

\footnotetext{
${ }^{2}$ Women are a smaller proportion of the prison population - about $7 \%$, although the number of women prisoners continues to increase. More information is available at https://www.bop.gov/about/statistics/statistics_inmate_gender.jsp.
} 
Deputy Assistant Secretary of Defense 2014; Bureau of Justice Statistics 2015).

\section{Socially Concentrated Experiences}

Secondly, these two institutions are comparable because both the military and criminal justice system are socially concentrated experiences, isolated to particular groups of people, particularly those who fall in the lower socio-economic end of the distribution (MacLean and Elder 2007). Because of this, the experiences of being incarcerated or in the military are distant phenomena for most Americans. Individuals disproportionately enter these institutions from specific social locations; race, socioeconomic status, and gender are all determinants of social location. Among high school seniors, military enlistment is lower for individuals with collegeeducated parents, and those with higher grades and plans to attend college are less likely to enlist (Bachman et al. 2000). Additionally, enlistment is predicted by gender - men are more likely to enlist than women - and African Americans and Hispanics are more likely to enlist than Whites (Bachman et al. 2000; Military Leadership Diversity Commission 2010). Both social location and geographical location influence the propensity of joining the military or being incarcerated. For example, in one year, $42 \%$ of individuals entering the military as enlisted and commissioned personnel came from Southern states (Segal and Segal 2004). Military service is increasingly becoming socially isolated within certain families; in this way military experience is a family affair as there is a correlation between parent and child military service (Eikenberry and Kennedy 2013). Since September 11, 2001, less than 1\% of the current population is active military at any given time, ${ }^{3}$ and $5 \%$ have a family member who has served in the military. Because of this, the average American does not have an intimate experience with a veteran (Schultz and Chandrasekaran 2014; Segal and Segal 2004).

Similarly, certain groups of people are disproportionately incarcerated. For instance, of African American young men who dropped

\footnotetext{
${ }^{3}$ This can be compared to World War II, when $12 \%$ of the American population served in the military (Segal \& Segal 2004).
} 
out of high school, $37 \%$ were incarcerated in 2008, compared to less than $1 \%$ of the general population (Western and Pettit 2010). Columbia University's Spatial Information Design Lab and Justice Mapping Center have mapped "million dollar blocks," neighborhood blocks that have such a high concentration of residents incarcerated that states are spending over a million dollars a year to incarcerate residents from a single block (Kurgan and Cadora 2016). This is a significant expenditure given that the average annual cost of incarceration per person is $\$ 28,000$ in state prisons and about $\$ 30,600$ in federal facilities (Bureau of Prisons 2015; James 2015). The maps suggest that in these communities, the criminal justice system is the most prevalent governmental institution (Kurgan and Cadora 2016). The high rate of incarceration of young African American men in particular has resulted in systemic exclusion and disadvantage for this demographic (Alexander 2010; Western 2002). Because incarceration is very concentrated in a small "underclass" segment of the population, this institution represents an exotic experience for most mainstream Americans (Western and Pettit 2010).

\section{A Changed Relationship with the State}

Finally, both institutions change a veteran or former prisoner's relationship with the state upon exiting. Formerly incarcerated individuals often experience "civil death," which includes disenfranchisement, inability to serve on a jury, and limited eligibility for student financial aid via Pell Grants (Mallory 2015; Miller and Spillane 2012). Previous research demonstrates how the formerly incarcerated are particularly discriminated against in the labor market, and how incarceration has a negative effect on wages (Pager 2003; Western 2002). Pager (2003) explains that the negative label affixed to former prisoners is a unique stratification mechanism in that it is the state that credentials individuals in a way that leads to social exclusion and discrimination (942, emphasis added). Many formerly incarcerated individuals also remain under state control post-release, as they must meet parole and probation requirements. About 4.7 million people, which equates to about 1 out of every 52 U.S. adults, are under community supervision at any point in time (Bureau of Justice Statistics 2015). Given that about 590,400 people are released 
annually from state and federal prisons, this trend will not decrease anytime soon (James 2015).

Conversely, veterans have myriad benefits they are entitled to upon leaving military service, including healthcare, education benefits, and access to home loans (Department of Defense 2016b; Wright 2012). Unlike the discrimination former prisoners experience in the job market, veterans have access to preferential hiring policies in the public sector and collective social capital (Lewis 2013; MacLean and Kleykamp 2014). Veterans are able to flexibly invoke this label; Feinstein (2015) found that veterans use information management techniques to navigate potential stigma in the job market, selectively disclosing military service when it is beneficial (16). The choice of whether or not to disclose one's veteran or former incarceration status is not an option for former prisoners, especially in the job market. While there may be differences in the salience of the label and the removal or addition of benefits, both formerly incarcerated individuals and veterans exit their respective institutions with changed relationships with the state.

\section{Similar Outcomes}

While there are important differences between life as a former prisoner and life as a veteran, especially the stigma of a criminal record versus the positive status afforded to veterans, these populations have similar outcomes on a number of measures (MacLean and Kleykamp 2014; Pager 2003). For example, both veterans and formerly incarcerated individuals have a higher rate of divorce than their peers (Glantz 2009; Massoglia, Remster, and King 2011). Veterans also have higher rates of unemployment, poverty, homelessness, alcoholism, and mental health challenges than their nonveteran peers, presenting similar challenges to obstacles formerly incarcerated people encounter (Glantz 2009; Maclean 2010; MacLean and Kleykamp 2014; Pager 2003; Schultz and Chandrasekaran 2014; Western 2002). Despite anticipated differences in outcomes, both veterans and former prisoners face similar reintegration challenges. These transition difficulties are evident for members of the dominant group who fit the archetypical image of veterans and former 
prisoners, but these problems may be amplified for members of marginalized groups.

Moving beyond the homogenous labels of "former prisoner" and "veteran," it is likely that reintegration processes differ for those who do not fit the model narrative. Academic research, social service programs, and public policies have typically been designed for the model veteran and former prisoner; intersectional analysis is an apt tool to rectify the lack of attention to women and LGBT individuals within these two institutions. In the section that follows, I discuss what an intersectional analysis would entail and then review intersectional themes in the existing literature specific to those with marginalized gender identities and sexual orientations. Beyond attention to LGBT identities, I also examine whether studies account for the institutional forces and systems of power that interplay with reintegration transitions.

\section{INTERSECTIONAL ANALYSIS}

Intersectionality is a framework that has been adopted in an increasing number of disciplines, and is being applied by both scholars in the academy and practitioners in the field. While many studies employing intersectionality grapple with how differences in social location - such as race, gender, sexuality, or class - influence individuals' lived experiences, intersectionality is also beneficial for examining macro-level structural and systemic forces. However, this institutional analysis is less tangible and is not used as frequently (Collins 2015). A number of scholars have proposed that robust intersectional analyses would move beyond the descriptive and also focus on an examination of structures and systemic power systems (e.g. Bowleg 2008; Cho, Crenshaw, and McCall 2013; Choo and Ferree 2010; Hancock 2007). Thus, the goal of this approach is not a disjointed, additive model of oppression essentializing specific social identities, but instead an analysis of how various social divisions are intertwined and mutually reinforcing as they subjectively construct identities (Yuval-Davis 2006, p. 205). Or, as Chun, Lipsitz, and Shin (2013: 923) say, it re-orients the point of analysis to reveal the political processes that define identities, instead of identities defining politics 
(Tomilson 2013: 996). While there is identification of what this systemic, process-level of analysis entails, few studies are able to capture this scale.

Specific tools for conducting this type of systemic analysis have been developed by several authors. Choo and Ferree (2010: 135) propose a systemic-centered approach, which recognizes that there is no one social process producing a singular main effect, as inequalities transform social structures at all levels and in all institutional contexts. This methodological framework incorporates the complexity of the multiple, interlocking systems that influence individual experiences. Operating in this way, intersectional analyses move beyond comparing different social groups, and instead center the findings within the context of structural inequality and unequal power relations (Bowleg 2008). Intersectional analyses also need to be cognizant of the rhetoric around "giving voice" to marginalized groups and pointing out differences in opposition to a mythical norm (Choo and Ferree 2010: 133). For instance, if LGBT veterans and former prisoners are always compared to the norm of heterosexuals, their experiences will perpetually seem different and unusual. Finally, intersectional analysis can be maximized when methodological frameworks focus on relationships rather than locations, and recognize a fluidity of knowledge and power across levels of social organization rather than a static hierarchy of stratification processes (Choo and Ferree 2010: 146). Thus, applying an intersectional perspective requires being attuned to multiple, interlocking systems and institutions which effect individual experiences while simultaneously recognizing the interactive flow of individuals influencing these structures.

\section{ANALYSIS: AN INTERSECTIONAL LITERATURE APPROACH}

I conducted extensive database searches to review the existing literature on veteran and former prisoner reintegration, with a focus on articles published in the last decade, and especially those published since 2010. This timeframe was chosen based on the premise that intersectionality is a relatively new construct (Davis 2008), LGBT-related military and incarceration policy changes have predominately taken place within the last decade, and out of curiosity about how recent scholarship 
employed intersectionality as a methodological tool. I made exceptions to this parameter in a few cases where a cornerstone article was especially relevant and influenced future scholarship. ${ }^{4}$ When I found relevant articles that appeared to be intersectional - I used a variety of search terms beyond the word "intersectionality" to achieve this - I scanned the References to see if there were additional articles that were relevant, and if so, looked those up and used the same strategy with that article's citations. By using this method, I was able to approach this search with both breadth and depth.

\section{Main Themes}

My review found that the existing literature, if it includes any intersectional analysis, is mostly descriptive, describing categorical identity differences. The articles that incorporate gender treat it as a binary of men and women, with little to no discussion of transgender individuals or fluid gender identity. While a few articles discussed the intersection of race and gender, these were generally limited. There is a dearth of articles on sexual orientation, with almost no discussion of how LGB-status may influence reintegration outcomes for veterans or former prisoners. Finally, very few articles examined overlying systems and structures that influence gender identity and sexual orientation within the military and prison systems or subsequent reintegration processes. In the proceeding section, I identify gender identity and sexual orientation themes, note gaps where more research is needed, and examine why these holes in the literature exist.

\section{Gender Identity as Binary}

There have been a number of articles on former prisoner re-entry in the last five to ten years that include empirical studies of women, but most analyses only include the binary categories of men and women. These articles note that previous literature only focused on men, and thus a (binary) gender-specific lens is needed. This call for a gender lens largely originated with Bloom, Owen, and Covington (2003) who proposed a

\footnotetext{
${ }^{4}$ Most notably, Bloom, Owen, and Covington (2003)
} 
gender-responsive strategy for women in the criminal justice system, including re-entry. While most studies incorporating gender focused on women, one study centered on formerly incarcerated men as the point of analysis. Based on interviews with seven young men and their family members, Martinez and Leverentz (2014) concluded that gender has an influence on the social support - emotional, instrumental, and financial young men receive as they transition from prison back to their communities. All seven of their interviewees were men of color; six identified as African American and one as Mexican. While these young men received support from female relatives, they served as role models and guides for men in their own generation, such as brothers and cousins (Martinez and Leverentz 2014).

Most of the articles centered on formerly incarcerated women and used qualitative methodology via interviews. While these studies noted the racial make-up of their sample, most did not include race as a key point of analysis in the findings or discussion. For example, Cobbina and Bender (2012) interviewed 26 incarcerated women, examining perceptions of their upcoming release and reintegration plans. They noted that $54 \%$ were African American and 46\% were Caucasian, but presented the findings in the aggregate. Similarly, Barrick, Lattimore, and Visher (2014) interviewed 255 women one month prior to release and at regular intervals post-release to ascertain how social ties with friends and family during incarceration relate to social support upon release. Their analysis did include demographic variables such as race and age, but this was not a central part of their analysis. In their re-entry study with women who were within six months of release, Hunter and Greer (2011) also had a racially diverse sample among 41 interviews, but did not discuss any racial differences among the women in the results. The same pattern exists in qualitative studies using interviews in a number of other recent articles about the re-entry of formerly incarcerated women (Clone and DeHart 2014; Cobbina 2010; Hlavka, Wheelock, and Jones 2015; Leverentz 2010; Weiss, Hawkins, and Despinos 2010). These studies miss an opportunity by presenting results for women as a monolithic category and not breaking down potential differences by race/ethnicity. Even if the results were similar across racial groups, this would be worth noting as it would 
suggest gender might be more salient than race when formerly incarcerated women re-enter their communities.

One of the most intersectional articles on former prisoner re-entry incorporating gender included a quantitative study. Huebner et al. (2010) analyzed how elements of incarceration, social relationships, community context, and race influenced the occurrence and timing of recidivism for women who were former prisoners. Their sample only incorporated Black and White women, but the authors noted the lack of Hispanic women and other women of color as a limitation of the study. Presenting how the results differed by race, type of incarceration experience, and community factors allowed for a more robust understanding of the nuanced experience of formerly incarcerated women.

There is very little research specifically examining how gender influences veteran reintegration and in what ways women or trans* veterans may have different reintegration experiences than male veterans. The studies that do exist focus on philosophical and empirical arguments of whether women should serve in the military (see Snyder 2003) or the mental health implications of sexual assault and harassment for reintegration (see Bell, Turchik, and Karpenko 2014; Kimerling et al. 2010). Examining specifically how gender influences the veteran reintegration experience appears to be a ripe opportunity for future research.

The majority of articles on both veteran and former prisoner reintegration treated gender as a binary of men or women, which leaves a large gap in the literature on transgender and gender non-conforming individuals. I did not find any articles on former prisoner re-entry that included discussion of gender identity beyond men or women. I only found one article on transgender veterans, and it largely focused on the implications for transgender veterans receiving healthcare (Yerke and Mitchell 2013). The authors noted that transgender individuals are formally barred from serving in the U.S. Military, ${ }^{5}$ and many report discrimination in the Department of Veterans Affairs (VA) healthcare

\footnotetext{
${ }^{5}$ The Pentagon lifted the ban on transgender service members in June 2016.
} 
system. The VA instituted a policy in June 2011 to establish equitable and respectful care for transgender veterans, but research has yet to address the impact of this policy (Yerke and Mitchell 2013). Recognizing a fluid approach to gender identity remains a gap in the literature.

\section{Race \& Gender}

Several studies went beyond only using a gender framework or only looking at racial differences among men to include both a race and gender analysis. While slightly outside the sphere of a typical social science article, a UCLA Law Review article by Lipsitz (2012) examines how Black and Latina women are especially vulnerable to surveillance, arrest, and incarceration because of housing and employment discrimination. Addressing key re-entry concerns for women of color based on race and gender discrimination, Lipsitz (2012) concludes by proposing litigation, legislation, and social mobilization strategies to address the intersectional dynamics of mass incarceration and re-entry. Chiricos and his colleagues (2007) use a similar intersectional frame to reflect how labeling and stigma influence recidivism. Chiricos et al. (2007) found the consequence of stigma to be greater for those convicted of a felony who were adjudicated as guilty - and thus labeled as a "felon" - than for those who had adjudication of guilt withheld (Chiricos et al. 2007: 570). This effect was stronger for women compared to men, and for White men compared to Black and Hispanic men (570). The authors conclude that the influence of labeling is more intense for those who are typically considered less likely to recidivate (570). Thus, if it is assumed a person has a formal label, the effect of the label is not as intense.

Within the military, Lundquist (2008) analyzed whether there were differences in job satisfaction based on race or gender structural conditions. Her findings indicated that structural inequality, as opposed to cultural differences, most influenced the racial disparities in job satisfaction as a service member (493). Lundquist (2008) also recognized that there is a gap in the literature on the experience of Latinos who serve in the military. Cooney and colleagues (2003) examined race and the socioeconomic status of women veterans, noting that previous research on 
whether military service influenced socioeconomic status excluded women. Overall, women veterans did not have higher earnings or family income compared to their civilian counterparts (Cooney et al. 2003). However, results indicated that Black women did better, by facing less of an earnings penalty, than White women. The authors interpret this racial difference as a manifestation of structural inequality: White women have more opportunities and advantages in the civilian labor market, so the comparison between veterans and non-veterans is more distinct, while Black women have fewer opportunities in the civilian labor market, so the military allows them to "keep pace" with their civilian counterparts (Cooney 2003: 77-78). While the military has implemented many policies promoting racial equity (Armor and Gilroy 2010, although also see Burk and Espinoza 2012), these results suggest the benefits do not necessarily extend to all groups, especially regarding gender identity and sexual orientation. These articles, which incorporate more than one identity category, begin to lay a framework for building an intersectional analysis.

\section{Sexual Orientation}

There is largely an absence of literature on the sexual orientation of veterans and former prisoners. I found no studies that examined the sexual orientation of formerly incarcerated individuals. The literature on veterans and sexual orientation existed primarily in psychology and counseling journals, and largely focused on the mental and physical health of LGBT veterans (see Blosnich, Mays, and Cochran 2014; Johnson and Federman 2013; Kauth et al. 2014; Mattocks et al. 2015; Sherman et al. 2014). While it is difficult to quantify the number of veterans who identify as LGBT as the VA does not maintain records on this information, many LGBT veterans report discriminatory treatment, or at minimum, an unwelcome environment at VA healthcare facilities (Sherman et al. 2014). Hinting at structural dynamics, Sherman and colleagues (2014) found that simple language changes, such as referring to "partners" and "committed relationships" instead of solely "wife/husband "and "marriage," could make a big difference in creating an inclusive environment (441). My review found that these clinically oriented articles refer to LGBT veterans as "sexual minorities," signaling the categorization of LGBT veterans as 
"the other" - a group to be dealt with - instead of examining institutional structures and the social construction of sexuality leading to the marginalization of these veterans in the first place. This suggests that there is a lack of empirical research on sexuality within the Sociological subfields of Military Studies and Criminology.

\section{Scale, Structures, and Systems}

An additional tool offered by intersectional analysis includes simultaneously examining multiple social scales, ranging from micro-level interpersonal interactions to meso-level community structures, all the way to macro-level national institutions and international contexts (Mahler, Chaudhuri, and Patil 2015). Several studies in my review applied an intersectional lens by incorporating different levels of scale into their analysis. For example, Sherman and colleagues (2014) incorporated two levels of scale in their study of LGBT veterans: a micro-level analysis via surveys and focus groups with LGBT veterans and a meso-level analysis of VA healthcare providers in two cities. The structural analysis of VA facilities allowed the authors to ascertain the lack of a welcoming environment for LGBT veterans. Another approach includes that of Scroggins and Malley (2010), who conducted a content analysis of 155 reentry programs in the 10 largest metropolitan areas in the United States. This meso-level analysis offers a unique perspective by identifying structural dynamics of re-entry programs, with results indicating that reentry programs generally do not meet the needs of women. Different levels of scale can also be realized through geographical consideration. Schnittker and Bacak (2013) contextualized differences in stigma among formerly incarcerated men by comparing subjective status both in local communities and the United States broadly. By situating their results in both a local and national context, the findings offer a unique glimpse into how a stigmatized status matters not just among one's local network, but also throughout the country. Finally, Western (2002) shows that a period of incarceration not only leads to reduced wages, but also a reduced rate of wage growth over the life course. By positioning the results in this framework, Western (2002) incorporates a broader scale; not only is there wage disparity at an individual level for former prisoners, this wage 
mobility structure has an aggregate consequence on social inequality for men of color.

In addition to scale, the explicit study of structures and systems is paramount to intersectional analysis. While most of the aforementioned studies focused on individual level outcomes, there are a few exceptions. Michelle Alexander's The New Jim Crow (2010) highlights the systemic forces behind mass incarceration, focusing on how African American men are marginalized and oppressed via the criminal justice system, both before and after incarceration. While one of the only sources that addresses structures and systems of power, this book has limited intersectional analysis because it only focuses on Black men, with no analysis of how those identifying as LGBT may have unique experiences within the criminal justice system. Western and Pettit (2010) and MacLean and Elder (2007) both address how incarceration and the military, respectively, are institutions that can perpetuate social inequality. These articles provide important structural perspectives that could be used to inform future research on how institutions such as the military and criminal justice system act as stratifying forces by influencing life outcomes after exiting these institutions.

\section{DISCUSSION}

\section{The Need for Intersectional Analysis}

As true with most populations, there is no single homogenous experience of incarceration or serving in the military, yet empirical studies and public policies often ignore important within-group differences. For instance, in addition to gender identity and sexual orientation, the influence of military service on various measureable outcomes depends on context, such as the time period and place. Veterans' experiences will be varied based on whether they were drafted or served in an all-volunteer force, whether they served during war or peace time, and whether or not they experienced combat (MacLean and Elder 2007). In addition to these contextual dynamics, MacLean \& Elder (2007) suggest the need for future research to make use of an intersectional analysis, especially regarding 
how military experience affects outcomes based on race, gender, and socioeconomic status.

The lack of research on the experiences of those who are transgender, gender non-conforming, and LGB in both the former prisoner and veteran literature emphasizes the need for an intersectional analysis that moves beyond gender and racial binaries of men/women and Black/White categorizations. Beyond academic insight, this is increasingly pertinent for the lived experiences of those engaging with the military and prison systems. In recent years, the military's exclusion of individuals identifying as LGBT has ended and all military roles are now open to women (Department of Defense 2011; MacLean and Elder 2007; Rosenberg and Philipps 2015; Rosenberg 2016). Similarly, women are being incarcerated at a faster rate than men, and there is increasing attention to the needs of LGBT individuals among the correctional community (Sontag 2015; Bureau of Justice Statistics 2015). Research is needed to better understand the unique experiences of these populations.

\section{Why is the Literature Not Intersectional?}

Recognizing that the intersectional research on former prisoner and veteran reintegration has been very limited, but that many authors recognize the need for more of an intersectional analysis, why does this gap in the literature exist? One issue is that institutionalized populations are often left out of survey analysis, including those who are incarcerated and those serving in the military (MacLean and Elder 2007; Western and Pettit 2010). Population-level facts are being produced while systemically excluding these groups from analysis, contributing to the marginalization they face (Western \& Pettit 2010). This is compounded for LGBT-related data, as many survey instruments do not include questions about gender identity and sexual orientation, further contributing to the lack of reliable data on formerly incarcerated LGBT individuals and veterans.

Secondly, the research that does exist on veterans and those formerly incarcerated focuses on the model narrative - veterans as straight White men and former prisoners as straight Black men. Data collection is one part of the problem, as survey instruments tend to ask identity-based, 
additive questions (e.g. "check all that apply") which mask the complexity of actual lived experiences (Bowleg 2008). While identity is shaped by multi-faceted lived experiences, questions that ask respondents to separate and rank whether "discrimination based on their race, gender, and/or sexual orientation" lead to a particular outcome do not adequately capture the nuance of interlocking identities shaped by structural oppression (Bowleg 2008: 316).

Additionally, to use an identity framework to better understand the experiences of those who do not fit this image, quantitative analysis can be challenging due to sample size. In order to claim statistical significance, the sample size needs to be large enough to make generalizable claims about a particular demographic (Wehrman 2011). This could be why most of the studies that do reveal results by race or gender follow the binary of men/women or Black/White; these are likely the only groups that had big enough samples to present statistically significant results. However, many of the studies I reviewed, especially those examining gender, used interviews to collect data. These authors could have presented the results in a more intersectional manner since statistical significance is not a goal of qualitative studies.

Finally, some may argue that focusing on LGBT individuals within these two institutions - prison and the military - is not a good use of time or resources because they represent such a small number of people. Why would a better understanding of the unique experiences of these marginalized groups matter to broader society? Hum and Simpson (2003) have referred to this as the "progression to the small" in which,

The social circumstances of a small and narrowly defined group may not offer many lessons for a wider population. From a more practical level, a narrowly constituted group may be ineffective in marshaling voice for their circumstances or garnering political support to influence policy. The "progression to the small" can be quite unforgiving.

While studying LGBT former prisoners and veterans may represent a "small n" when compared to all formerly incarcerated persons 
or veterans, they are a sizeable group in their own right. For instance, there are an estimated 134,000 transgender veterans, with an additional 15,000 on active duty and in the National Guard or Reserve forces (Gates and Herman 2014). Women and LGBT individuals will likely continue to be engaged with the military and criminal justice system at high rates. ${ }^{6}$ Furthermore, research on women and LGBT veterans and former prisoners - oppressed groups - illustrates how gender identity and sexual orientation norms may differ between oppressed and dominant groups, which is beneficial to both scholars and policy makers. Thus, designing research to better understand these nuances could be advantageous in both designing appropriate policies and contributing to a broader understanding of social inequality.

\section{How Could Intersectional Analyses Improve Our Understanding?}

Applying an intersectional framework to former prisoner and veteran reintegration provides a mechanism to understand the deinstitutionalization processes for LGBT individuals, who likely have distinct experiences compared to those who fit the model archetype. This has significant policy implications for the experiences of LGBT veterans and those formerly incarcerated. Current transition resources are built for the model veteran and former prisoner, thus leaving out individuals who do not fit that dominant image (Bloom et al. 2003; Wright 2012). Because research is often designed to use the dominant group as a reference category and not include those with marginalized identities, there is limited understanding of the unique reintegration experiences for LGBT individuals. Innovative policy solutions targeting marginalized groups require policy makers to understand the social location of the people they are trying to assist, and how their social locations structure their engagement with policy changes (Manuel 2006: 196). Exploring how institutions and systems of power amplify or moderate the stigmatization

\footnotetext{
${ }^{6}$ Research on a specific group of veterans could lead to targeted programs that result in smoother reintegration experiences. If women and LGBT veterans have a successful transition experience, this may result in other women and members of the LGBT community perceiving the military as a positive experience, potentially bolstering military recruitment of these groups.
} 
of LGBT individuals can lead to increased understanding of gaps in public policy and the need for more targeted interventions for particular demographic groups. The current "one size fits all" approach ignores important differences in the experiences of LGBT veterans and former prisoners.

Finally, applying an intersectional framework allows for moving beyond the individual to understand how the military and prison function as institutions that perpetuate social inequality. Serving in the military and being incarcerated are socially concentrated experiences that change veterans' and former prisoners' relationship with the state (Maclean 2010; Western and Pettit 2010). A structural analysis of these institutions, coupled with the empirical evidence about the ongoing discrimination the LGBT community continues to face, could illuminate how state institutions affect the life course of those with marginalized gender identities and sexual orientations. While it is outside the scope of this paper to address the stratifying nature of these institutions, an intersectional framework is well poised to take on this systemic level of analysis in future research.

\section{CONCLUSION}

Exiting prison and leaving the military are critical transitions, and limited knowledge about the unique needs of LGBT veterans and former prisoners may lead to ineffective policies that undermine successful reintegration. An intersectional framework can be employed to better understand those with marginalized gender identity and sexual orientation statuses, yet challenges remain. This review of former prisoner re-entry and veteran reintegration found that existing intersectional empirical studies reflect binary norms based on individual categories, not accounting for any fluidity of other gender or sexual orientation identities. There is very limited structural analysis of how systems of power influence the reintegration experiences of those with LGBT identities. This lack of system-centered intersectional analysis may be due to the nature of excluding institutionalized populations from survey analysis, small sample sizes, and the perceived importance of studying marginalized populations, 
especially those who identify as LGBT. Further research should explore this in more detail and apply a structural lens to the stratifying nature of prison and the military as institutions, leading to a broader understanding of institutionalized social inequality. A robust intersectional analysis of veteran and former prisoner reintegration has the potential to make public policy contributions by recognizing the nuanced experiences of reintegrating LGBT individuals, recognizing that a "one size fits all" approach is not effective for everyone, which is especially relevant considering recent LGBT-related policy changes.

\section{REFERENCES}

Alexander, Michelle. 2010. The New Jim Crow. New York: The New Press.

Armor, David J. and Curtis L. Gilroy. 2010. "Changing Minority Representation in the U.S. Military." Armed Forces \& Society 36:223-46.

Bachman, Jerald G., David R. Segal, Peter Freedman-Doan, and Patrick M. O’Malley. 2000. "Who Chooses Military Service? Correlates of Propensity and Enlistment in the U.S. Armed Forces." Military Psychology 12:1-30.

Barrick, K., P. K. Lattimore, and C. a. Visher. 2014. "Reentering Women: The Impact of Social Ties on Long-Term Recidivism." The Prison Journal 94:279-304.

Bell, Margret E., essica A. Turchik, and Julie A. Karpenko. 2014. "Impact of Gender on Reactions to Military Sexual Assault and Harassment." Health \& Social Work 39: 25-33.

Bloom, Barbara, Barbara Owen, and Stephanie Covington. 2003. GenderResponsive Strategies: Research, Practice, and Guiding Principles for Women Offenders. Retrieved (https://s3.amazonaws.com/static.nicic.gov/Library/018017.pdf). 
Blosnich, John R., Vickie M. Mays, and Susan D. Cochran. 2014.

"Suicidality Among Veterans: Implications of Sexual Minority

Status." American Journal of Public Health 104: 535-37.

Bowleg, Lisa. 2008. "When Black + Lesbian + Woman Does Not Equal Black Lesbian Woman: The Methodological Challenges of Qualitative and Quantitative Intersectionality Research.” Sex Roles 59: $312-25$.

Bureau of Justice Statistics. 2015. Census of Jails: Population Changes, 1999-2013. Retrieved (http://www.bjs.gov/content/pub/pdf/cjpc9913.pdf).

Bureau of Prisons. 2015. Annual Determination of Average Cost of Incarceration. Retrieved (https://www.federalregister.gov/documents/2015/03/09/201505437/annual-determination-of-average-cost-of-incarceration).

Burk, James and Evelyn Espinoza. 2012. "Race Relations Within the US Military." Annual Review of Sociology 38:401-22.

Chiricos, T. and S. Eschholz. 2002. "The Racial and Ethnic Typification of Crime and The Criminal Typification of Race and Ethnicity in Local Television News." Journal of Research in Crime and Delinquency 39(4):400-420.

Chiricos, Ted, Kelle Barrick, William Bales, and Stephanie Bontrager. 2007. "The Labeling of Convicted Felons and Its Consequences for Recidivism." Criminology 45(3):547-81.

Cho, Sumi, Kimberle Williams Crenshaw, and Leslie McCall. 2013. "Toward a Field of Intersectionality Studies: Theory, Applications, and Praxis." Signs 38(4):785-810.

Choo, Hae Yeon and Myra Marx Ferree. 2010. "Practicing Intersectionality in Sociological Research: A Critical Analysis of Inclusions, Interactions, and Institutions in the Study of Inequalities." Sociological Theory 28(2):129-49. 
Chun, Jennier Jihye, George Lipsitz, and Young Shin. 2013.

"Intersectionality as a Social Movement Strategy: Asian Immigrant Women Advocates.” Signs 38(4):917-40.

Clone, Stephanie and Dana DeHart. 2014. "Social Support Networks of Incarcerated Women: Types of Support, Sources of Support, and Implications for Reentry." Journal of Offender Rehabilitation 53(7):503-21.

Coates, Ta-Nahisi. 2015. "The Black Family in the Age of Mass Incarceration." The Atlantic, October. Retrieved (http://www.theatlantic.com/magazine/archive/2015/10/the-blackfamily-in-the-age-of-mass-incarceration/403246/).

Cobbina, Jennifer E. 2010. "Reintegration Success and Failure: Factors Impacting Reintegration Among Incarcerated and Formerly Incarcerated Women." Journal of Offender Rehabilitation 49(3):210-32.

Cobbina, Jennifer E. and Kimberly A. Bender. 2012. "Predicting the Future: Incarcerated Women's Views of Reentry Success.” Journal of Offender Rehabilitation 51(5):275-94.

Collins, Patricia Hill. 2015. "Intersectionality's Definitional Dilemmas." Annual Review of Sociology 41(1):1-20.

Cooney, Richard T., Mady Wechsler Segal, David R. Segal, and William W. Falk. 2003. "Racial Differences in the Impact of Military Service on the Socioeconomic Status of Women Veterans." Armed Forces \& Society 30(1):53-85.

Davis, Kathy. 2008. "Intersectionality as Buzzword: A Sociology of Science Perspective on What Makes a Feminist Theory Successful." Feminist Theory 9(1):67-85. 
Department of Defense. 2011. Repeal of 'Don't Ask, Don't Tell' (DADT):

Quick Reference Guide. Retrieved

(http://archive.defense.gov/home/features/2010/0610_dadt/Quick_

Reference_Guide_Repeal_of_DADT_APPROVED.pdf).

Department of Defense. 2016a. "Secretary of Defense Ash Carter

Announces Policy for Transgender Service Members." NR-246-16.

Retrieved October 26, 2016 (http://www.defense.gov/News/News-

Releases/News-Release-View/Article/821675/secretary-of-

defense-ash-carter-announces-policy-for-transgender-servicemembers).

Department of Defense. 2016b. "Transition Assistance Program.” DOD

TAP. Retrieved June 24, 2016 (https://www.dodtap.mil).

Eikenberry, Karl W. and David M. Kennedy. 2013. "Americans and Their

Military, Drifting Apart.” The New York Times (May 26).

Retrieved

(http://www.nytimes.com/2013/05/27/opinion/americans-andtheir-military-drifting-apart.html?_r=1).

Feinstein, Y. 2015. “The Thin Line between 'Crazy' and 'Hero':

Exploring the Multiple Statuses of US Veterans in a WorkTherapy Program." Armed Forces \& Society 41(1):3-22.

Gates, G. and J. Herman. 2014. "Transgender Military Service in the United States.” The Williams Institute, UCLA School of Law 1-5. Retrieved (http://williamsinstitute.law.ucla.edu/wpcontent/uploads/Transgender-Military-Service-May-2014.pdf).

Glantz, Aaron. 2009. The War Comes Home: Washington's Battle Against America's Veterans. Berkeley: University of California Press.

Goffman, Erving. 1961. Asylums: Essays on the Social Situation of Mental Patients and Other Inmates. Garden City, NY: Anchor Books.

Halvorson, Angela. 2010. Understanding the Military: The Institution, the Culture, and the People. 
Hancock, Ange-Marie. 2007. "Intersectionality as a Normative and Empirical Paradigm.” Politics \& Gender 3(2):41-45.

Hlavka, Heather, Darren Wheelock, and Richard Jones. 2015. "Exoffender Accounts of Successful Reentry from Prison." Journal of Offender Rehabilitation 54(6):406-28.

Huebner, Beth M., Christina DeJong, and Jennifer Cobbina. 2010. "Women Coming Home: Long-Term Patterns of Recidivism." Justice Quarterly 27(2):225-54.

Hum, Derek and Wayne Simpson. 2003. "Labour Market Training of New Canadians and Limitations to the Intersectionality Framework." Canadian Ethnic Studies 35(56):57-73.

Hunter, Vicki and Kimberly Greer. 2011. "Filling in the Holes: The Ongoing Search for Self Among Incarcerated Women Anticipating Reentry." Women \& Criminal Justice 21(3):198-224.

\section{James, Nathan. 2015. Offender Reentry: Correctional Statistics, Reintegration into the Community, and Recidivism.}

Johnson, Laura and Edward J. Federman. 2013. "Pathways and Barriers to Care for LGBT Veterans in the U.S. Department of Veterans Affairs (VA)." Journal of LGBT Issues in Counseling 7(3):218-35.

Justice, Department of. 2015. "Prison Rape Elimination Act." Office of Justice Programs. Retrieved October 26, 2016 (http://ojp.gov/programs/prisonrapeelimination.htm).

Kauth, Michael R. et al. 2014. "Access to Care for Transgender Veterans in the Veterans Health Administration: 2006-2013." American Journal of Public Health 104(4):532-34.

Kimerling, Rachel et al. 2010. "Military-Related Sexual Trauma Among Veterans Health Administration Patients Returning from Afghanistan and Iraq." American Journal of Public Health 100(8):1409-12. 
Kurgan, Laura and Eric Cadora. 2016. "Million Dollar Blocks.” Spatial Information Design Lab. Retrieved (http://spatialinformationdesignlab.org/projects/million-dollarblocks).

Lang, Nico. 2016. ““Orange Is the New Black' Could Help Save Trans Inmate Lives: Prisons Continue to Fail Women like Sophia." Salon (June 20). Retrieved (http://www.salon.com/2016/06/20/orange_is_the_new_black_coul d_help_save_trans_inmate_lives_as_prisons_continue_to_fail_wo men_like_sophia/).

Lerner-Kinglake, Jesse. 2016. "New Federal Guidance: Prisons and Jails Cannot House Transgender Prisoners by Anatomy." National Center for Transgender Equality. Retrieved October 26, 2016 (http://www.transequality.org/press/releases/new-federal-guidanceprisons-and-jails-cannot-house-transgender-prisoners-byanatomy).

Leverentz, Andrea. 2010. "People, Places, and Things: How Female ExPrisoners Negotiate Their Neighborhood Context." Journal of Contemporary Ethnography 39(6):646-81.

Lewis, Gregory B. 2013. “The Impact of Veterans' Preference on the Composition and Quality of the Federal Civil Service." Journal of Public Administration Research and Theory 23(2):247-65.

Lipsitz, George. 2012. "“In an Avalanche Every Snowflake Pleads Not Guilty': The Collateral Consequences of Mass Incarceration and Impediments to Women's Fair Housing Rights." UCLA Law Review 59(6):1746-1809.

Lundquist, Jennifer Hickes. 2008. "Ethnic and Gender Satisfaction in the Military: The Effect of a Meritocratic Institution." American Sociological Review 73(3):477-96. 
Maclean, Alair. 2010. "The Things They Carry: Combat, Disability and Unemployment among US Men." American Sociological Review 75(4):563-85.

MacLean, Alair and Glen H. Elder. 2007. "Military Service in the Life Course." Annual Review of Sociology 33(1):175-96.

MacLean, Alair and Meredith Kleykamp. 2014. "Coming Home: Attitudes toward U.S. Veterans Returning from Iraq." Social Problems 61(1):131-54.

Mahler, Sarah J., Mayurakshi Chaudhuri, and Vrushali Patil. 2015. "Scaling Intersectionality: Advancing Feminist Analysis of Transnational Families." Sex Roles 73(3-4):100-112.

Mallory, Jason L. 2015. "Denying Pell Grants to Prisoners: Race, Class, and the Philosophy of Mass Incarceration." International Social Science Review 90(1): Article 2.

Manuel, Tiffany. 2006. "Envisioning the Possibilities for a Good Life: Exploring the Public Policy Implications of Intersectionality Theory." Journal of Women, Politics \& Policy 28(3-4):173-203.

Martinez, Damian J. and Andrea Leverentz. 2014. "In It for the Long Haul: Exploring Gender Dynamics in Former Prisoner-Family Relationships." Journal of Qualitative Criminal Justice \& Criminology 2(1).

Massoglia, Michael, Brianna Remster, and Ryan D. King. 2011. "Stigma or Separation? Understanding the Incarceration-Divorce Relationship." Social Forces 90(1):133-55.

Mattocks, Kristin M. et al. 2015. "Perceived Stigma, Discrimination, and Disclosure of Sexual Orientation Among a Sample of Lesbian Veterans Receiving Care in the Department of Veterans Affairs." LGBT Health 2(2):147-53. 
Military Leadership Diversity Commission. 2010. "Propensity to Serve in the Armed Forces: Racial/Ethnic and Gender Differences, Trends, and Causes." Arlington, VA. Retrieved (http://diversity.defense.gov/Portals/51/Documents/Resources/Co mmission/docs/Issue Papers/Paper 12 - Propensity to Serve in Armed Forces.pdf).

Miller, B. L. and J. F. Spillane. 2012. "Civil Death: An Examination of Ex-Felon Disenfranchisement and Reintegration." Punishment \& Society 14(4):402-28.

Office of the Deputy Assistant Secretary of Defense. 2014. 2014 Demographics: Profile of the Military Community.

Pager, Devah. 2003. "The Mark of a Criminal Record." American Journal of Sociology 108(5):937-75.

Pellerin, Cheryl. 2015. "Carter Opens All Military Occupations, Positions to Women." U.S. Department of Defense. Retrieved October 26, 2016

(http://www.defense.gov/News/Article/Article/632536/carteropens-all-military-occupations-positions-to-women).

\section{"PREA Resource Center." 2016. "Prison Rape Elimination Act."}

Rosenberg, Matthew. 2015. "Pentagon Moves to Allow Transgender People to Serve Openly in the Military." The New York Times (July 13). Retrieved (http://www.nytimes.com/2015/07/14/us/pentagonplan-would-let-transgender-people-serve-openly.html).

Rosenberg, Matthew. 2016. "Transgender People Will Be Allowed to Serve Openly in Military." The New York Times (June 30). Retrieved (http://www.nytimes.com/2016/07/01/us/transgendermilitary.html?_r=0). 
Rosenberg, Matthew and Dave Philipps. 2015. "All Combat Roles Now Open to Women, Defense Secretary Says." The New York Times (December 3). Retrieved

(http://www.nytimes.com/2015/12/04/us/politics/combat-militarywomen-ash-carter.html?_r=0).

Schnittker, Jason and Valerio Bacak. 2013. "A Mark of Disgrace or a Badge of Honor?: Subjective Status among Former Inmates." Social Problems 60(2):234-54.

Schultz, Howard and Rajiv Chandrasekaran. 2014. For Love of Country. New York: Random House.

Scroggins, Jennifer R. and Sara Malley. 2010. "Reentry and the (Unmet) Needs of Women.” Journal of Offender Rehabilitation 49(2):14663.

Segal, David R. and Mady Wechsler Segal. 2004. “America's Military Population.” Population Bulletin 59(4):3-40.

Sherman, Michelle D. et al. 2014. "An Empirical Investigation of Challenges and Recommendations for Welcoming Sexual and Gender Minority Veterans Into VA Care." Professional Psychology: Research and Practice 45(6):433-42.

Snyder, R.Claire. 2003. "The Citizen-Soldier Tradition and Gender Integration of the U.S. Military." Armed Forces \& Society 29(2):185-204.

Sontag, Deborah. 2015. "Ashley Diamond, Transgender Inmate, Is Out of Prison but Far From Free.” The New York Times (September 24). Retrieved (http://www.nytimes.com/2015/09/25/us/ashleydiamond-transgender-inmate-out-of-prison-but-not-fullyfree.html).

Tomilson, Barbara. 2013. "To Tell the Truth and Not Get Trapped: Desire, Distance, and Intersectionality at the Scene of the Argument." Signs 38(4):993-1017. 
Wehrman, Michael M. 2011. "Examining Race and Sex Inequality in Recidivism." Sociology Compass 5(3):179-89.

Weiss, Josie a, Joellen W. Hawkins, and Carine Despinos. 2010.

"Redefining Boundaries: A Grounded Theory Study of Recidivism in Women." Health Care for Women International 31(3):258-73.

Western, Bruce. 2002. "The Impact of Incarceration on Wage Mobility and Inequality." American Sociological Review 67(4):526-46.

Western, Bruce and Becky Pettit. 2010. "Incarceration \& Social Inequality." Daedalus - American Academy of Arts \& Sciences 819.

Wright, James E. 2012. Those Who Have Borne the Battle: A History of America's Wars and Those Who Fought Them. edited by Public Affairs. New York.

Yerke, Adam F. and Valory Mitchell. 2013. "Transgender People in the Military: Don't Ask? Don't Tell? Don't Enlist!” Journal of Homosexuality 60:436-57.

Yuval-Davis, N. 2006. "Intersectionality and Feminist Politics." European Journal of Women's Studies 13: 193-209. 